\title{
The Central Pronouns in Nigeria's 2015 Presidential Debate: A Grammatical Analysis
}

\author{
Roseline A. Adejare ${ }^{1}$ \\ ${ }^{1}$ Department of Language, Arts and Social Science Education, Lagos State University, Ojo, Lagos, Nigeria \\ Correspondence: Roseline A. Adejare, Department of Language, Arts and Social Science Education, Lagos State \\ University, Ojo, Lagos, Nigeria. E-mail: abonego@yahoo.com
}

Received: September 23, 2017 Accepted: October 20, $2017 \quad$ Online Published: December 23, 2017

doi:10.5539/ijel.v8n2p56 URL: http://doi.org/10.5539/ijel.v8n2p56

\begin{abstract}
This grammatical analysis of the central pronouns in Nigeria's 2015 Presidential Debate aimed at determining their occurrence, semantic manifestations, typological and thematic distribution, and textual functions. Twenty-three central pronouns with a combined frequency of 2409 were identified and analysed using Quirk et al.'s (1985) framework. The result showed a 58\% representation and a frequency of 94.6 in 1000 words, with the forms we, you, it, I, they, our emerging the most frequent. Personal pronouns were a hundred times more frequent than reflexive pronouns and fourteen times more recurring than possessives. The 1 st person, 2nd person and 3rd person forms respectively represent approximately one-half, one-quarter, and one-third of total person contrast made; however, a dominance of plural over singular was seen and this was more pronounced with 2 nd person. Whereas the ratio of masculine to feminine was 22:1, neuter gender was generally dominant. A dominance of subjective case over objective case was revealed while genitive case featured as determinatives only. Pronominal choices were governed by theme, structure of responses, and idiosyncrasy, as $I$ was more concentrated under motivation for contesting than any other theme and under recognising and justifying the problem than specifying actions to be taken or making concluding marks. The multiple-authored texts used manifestly exposed the diversity of pronoun forms and their combinatory possibility, which was advantageous since the focus was not a given politician's idiolect but the use of an aspect of language in politics, namely the central pronouns.
\end{abstract}

Keywords: central pronouns, typological distribution, thematic distribution

\section{Introduction}

Analyses of the language of politics in the Nigerian research scene have been approached from the viewpoints of Discourse Analysis (DA), Critical Discourse Analysis (CDA), Systemic Functional Grammar (SFG), and Pragmatics with little or no input from grammar. Where some interest in grammar is expressed, the focus is on the sentence and clause with little attention paid to the smaller units that make up the whole. Pronouns suffer the greatest neglect in this regard as even existing analyses are shallow. Moreover, there is a general tendency to use written material or transcripts of "spoken texts" handed out to the media, with the size of the corpus often not indicated and the frequency of the grammatical items examined not determined. While difficulty in accessing and processing original spoken material may explain this trend, analysing discourse without grammar is not an analysis at all but a "running commentary" (Halliday,1985, p. xvii). Reference to three works will suffice. Opeibi's (2010) analysis of selected campaign texts aimed at partially assessing the centrality of English in the Nigerian political discourse is SGF-based and is restricted to the sentence (eleven only). Abdullahi-Idiagbon (2010) employs CDA to determine the ideologies underlying presidential campaign speeches, citing yours, mine, our, we, and $I$ only as pronouns used in "unique manners". Using pragmatics as tool, Oladimeji (2010) analyses twenty utterances chosen on the basis of speech act forms from the twenty-three-paragraph inaugural speech of President YarAdua and lists we, our, I, and this only as words used to "indicate role relationships and reference". A grammatical analysis as envisaged in this study will not focus on a select few but will account for all occurring central pronouns.

It is not improbable that the neglect of the pronoun is patently broad and universal. Even though the need for a greater attention to be paid to the pronoun word class and aspects of its description has long been recognised, not much seems to have been accomplished in that direction. For instance, Strang (1969) challenges grammarians to 
undertake a frequency survey of pronouns in different syntactic positions, but as recently as 2004 Andrew Radford observes that "a number of aspects of the syntax of pronouns remain to be clarified" (p. 40). This is an indication that there are gaps in the description of pronouns.

Against the foregoing background, this study undertakes a grammatical analysis of Nigerian political discourse by examining the occurrence and use of the central pronouns in the 2015 Presidential Debate. It particularly seeks to (a) identify all the central pronouns used by the debaters, (b) assign them to subclasses and determine their frequency of occurrence, (c) examine their semantic manifestations in terms of person, number, gender, and case, (d) determine their distribution with respect to the themes of the debate, and (e) illustrate how they contributed to achieving debaters' goals. The choice of the central pronouns is underscored by their shared grammatical similarities with respect to the four categories that define them.

\section{Literature Review}

This review of literature covers description of pronouns in the grammar and studies on their use in texts. It begins with a consideration of the pronoun as a word class.

\subsection{The Word Class Pronoun}

The traditional definition of the pronoun as a word used in place of a noun accords it a distinct word class status, though this is sometimes seen as unsatisfactory because what is often replaced comprises both the noun headword and determiner. Pronouns so much resemble nouns in their syntactic functions that the suggestion has been made that they be regarded as a subclass of nouns rather than a separate word class (Huddleston, 1984, pp.272\& 275; Bloor \& Bloor, 1990, p.15). But pronouns are sufficiently different from nouns that they must be treated separately: They are a closed system lacking in "intrinsic descriptive content" and, although they also have the capacity to follow prepositions, pronouns differ from common nouns by not following articles. Pronouns are moreover morphologically distinct in their possession of a three-term case system, a two-term number system, an overt gender system, and in making person contrast (Strang, 1969, pp.115-116; Quirk etal., 1985, p.335; Greenbaum, 1996, p. 83; Radford, 2004, p. 35). The research objectives clearly defined above are indicative of the view of the pronoun as a word class distinct from noun.

\subsection{Classification of Pronouns}

There is no agreement on the classification of pronouns. Pronouns are traditionally classified into personal (e.g., I), possessive (e.g., my), demonstrative (e.g., this), interrogative (e.g., what), relative (e.g., who), and indefinite (e.g., one) subtypes (Jespersen, 1933, pp.67-68), with the personal pronoun subclass inclusive of reflexive pronouns (e.g., myself).This has been described as "extremely heterogeneous" (Christophersen \&Sandved, 1969, p.59), leading to the emergence of diverse classificatory criteria summarised as follows:

1) Personal, possessive, and reflexive (Scott et al., 1968, p.27)

2) Personal (possessive inclusive), relative (Christophersen \&Sandved, 1969, p.52)

3) Personal, possessive, reflexive, reciprocal (e.g., each) (Huddleston, 1984, p.272; Greenbaum \& Nelson, 2002, pp. 98-102)

4) Central (comprising personal, possessive, reflexive), reciprocal, relative, interrogative, demonstrative, indefinite (Quirk et al., 1985, pp.345-346)

5) Possessive, wh-(e.g., who), that- (Bloor \& Bloor, 1990, p.18)

6) N-(e.g., one), Q- (e.g., all), D- (e.g., this), personal (inclusive of possessive) (Radford, 2004, pp.35-38).

Quirk et al. (1985) present the clearest classification and the most explicit and comprehensive description of the pronouns generally and the central pronouns particularly. With particular reference to our subject, they recognise the characteristics shared by personal, possessive and reflexive pronouns which others lack and which set pronouns apart from nouns and grouped them together under a descriptively most appropriate nomenclature. We have great sympathy for their treatment of the central pronouns and shall adopt it for the handling of our data beginning with its collection.

\subsection{The Central Pronouns}

Quirk et al. (1985, pp. 346-363) identify the central pronouns as a subclass of pronouns that share the similar characteristics of making person, number, gender, and case (most) distinctions. It is these characteristics which, more than anything else, more clearly differentiate pronouns from nouns and justify their treatment as a separate word class. The central pronouns comprise personal, reflexive, and possessive subtypes. Personal pronouns distinguish the speaker(s)/writer(s) from the listener(s)/ hearer(s) and the addressee (s), called 1st person (e.g., $I$, 
$w e$ ), 2nd person (you), and 3rd person (he/ she/ it; they) respectively. Personal pronouns are seen as "the most important and central class of pronouns" by virtue of their "frequency and grammatical characteristics". Reflexive pronouns "reflect another nominal element" in the subject position of the clause and have emphatic functions too (e.g., "I myself gave it to you"). Unlike personal pronouns, they make number distinction in the 2nd person (yourselflyourselves) and gender contrast in the 3rd person (himselfl herself /itself). Described as "the genitives of personal pronouns", possessive pronouns are distinguished in terms of the binary opposition of determinative and independent. The determinative subset is syntactically dependent and functions as determiners (e.g., my, our and your) while the syntactically independent subset (e.g., mine, ours, and yours) realises clausal elements as subject and as complement (See also Strang, 1969, pp.117 \&119; Huddleston, 1984, pp.287\&291-295; Greenbaum, 1996, pp.84\&166; Nelson, 2001, p.62; Greenbaum \& Nelson, 2002, p.101; Radford, 2004, p.38).

\subsection{Person, Number, Gender and Case in the Central Pronouns}

Quirk et al.'s (1985, pp.335-345) description of the categories person, number, gender and case are summarised as follows. All three subtypes of central pronouns make distinction in person, distinguishing among the speaker, the addressed, and the referent. The 1st person refers to the speaker/writer and can be singular $(I, m e, m y$, mine, myself) or plural (we, us, our, ours, ourselves). The 2nd person excludes the speaker/writer but includes the addressee; it comprises you which does not formally distinguish its singular and plural forms and your, yours, yourself, and yourselves. The 3rd person makes references to "third parties" not directly involved in the event coding process (excluding both speaker/writer and addressee) and has singular (he, him, his, himselff; she, her, hers, herself; it , its, itself) and plural (they, them, their, themselves) forms. Although personal, possessive and reflexive pronouns make number distinction, their singular and plural forms are morphologically unrelated. Moreover, the semantic contrast is not one v more than one; rather, it is "I plus one or more other person" for plural we and "you (singular) and one or more other persons, but not me" for plural you.

There are basically three gender contrasts, namely masculine (he, him, himself, and his), feminine (she, her, hers, and herself), and neuter (it, its, and itself). Gender distinction is restricted to the 3rd person singular forms. However, English lacks a gender-neutral 3rd person singular pronoun for references to both male and female and resorts to the plural they "in defiance of strict number concord". In their study of the perception of gender-related singular they by examiners, Yusuf and Olateju (2005, p.145) report that those who considered it incorrect after a noun phrase and marked it wrong were slightly higher than those who thought and acted otherwise. Originally, there were two case forms for nouns and pronouns called common case and genitive, but the five personal pronouns make a further distinction between subjective case (e.g., he) and objective case (e.g., him), effectively bringing the number to three: subjective, objective and genitive. The genitive case subdivides into determinative (e.g., $m y$ ) and independent (e.g., mine) subtypes .while the subjective and objective realise clausal elements as subject and object respectively. The personal pronouns you and it maintain a single form for both the subjective case and objective case. How frequently each of them makes case distinction is of interest to this study. (See also Strang, 1969, p.116; Christophersen \&Sandved, 1969, pp.53\&55; Huddleston, 1984, pp. 288-291; Greenbaum, 1996, p.169)

\subsection{Studies on the Pronouns in Texts}

Abdel-Moety (2015) adopts the SGF approach to analyse the personal pronouns $I$ and we in Hillary Clinton's TV interviews and reports that they represent individual viewpoint and collective perspectives respectively. Flores-Ferrañ's (2017) CDA study of Donald Trump's use of pronominal deictic expression centring on I, we, and you shows that while the all-inclusive and proximal we occurred more frequently in victory-related discourse the proximal $I$ featured in debates to draw attention to self. Hasan (2013) reports that while the out-group pronouns $(I, m y, m e)$ were almost twice as frequent as the in-group forms (we, our, us), Hosni Mubarak used the dominant 1st person singular far more frequently in his address to the Egyptian people and we more frequently in reference to the government and people. Whereas Hamdauoi's (2015) pragmatics-based analysis of the persuasive power of person deixis in Obama's speeches reveals nineteen pronouns, only the pronoun we was focused upon because it was the most recurring. Bello (2013) analyses President Goodluck Jonathan's 1831-word declaration of interest speech using Fairclough's (1998) model of CDA and reports that politicians use pronouns to position themselves and others. On the subject of political discourse, van Dijk (1997) points out that syntactic style is politically manipulated and that deictic pronouns are particularly used to denote political polarisation.

A comparative study of the use of pronouns in the US 2008 Presidential Debate is undertaken by Boyd (2013) who finds that though pronouns were generally more strategically used by both candidates, they were more 
strategically and more deliberately used by McCain to distance himself further from Obama and identify himself more closely with the American people. Although the current study is based on a presidential debate, it is not comparative and the participants are six times as many. Hắkansson (2012) compares George W. Bush's pronominal choices with Barrack Obama's based on a 30 000-word corpus, and reports that Obama used more personal pronouns than Bush and that the referents differed according to contexts while $I$ conveyed opinion and we expressed institutional identity. Gocheco's (2012) exploration of the use of pronouns in TV-mediated political campaign discourse in the Philippines aimed at identifying the predominant personal pronouns and their functions is a clear departure from the trend because the language is Tagalog and not English. The study's significance however lies in the choice of an existing description of the Tagalog pronominal system as theoretical framework and the possibility of accounting for all occurring forms in the corpus. As indicated above, the theoretical and descriptive framework adopted for this study is Quirk et al.'s (1985) articulation of the English central pronouns.

The study of pronominal use is not limited to political discourse. Carey et al. (2015), for example, investigate the extent to which narcissism is related to the use of the 1st person singular pronoun $I$ and find no statistically significant correlation between I-talk and narcissism despite the large-scale sample employed. Kuo's (1999) analysis of personal pronouns in thirty-six scientific journal articles shows that the 1st person pronoun was used more frequently than others and that a number of semantic references perform multiple functions. Tayeybi (2012) investigates the variations in personal pronoun use between English and Persian writers using forty-five medical research articles published in each language, and reports that no 1st person singular pronoun occurred in both corpora due to multiple authoring and that English scholars used more self-mention. Though cross-linguistic and on academic discourse, the study provides further justification for the presentational format proposed for the qualitative aspect of this work which is informed by the structure of the oral composition. Being samples of academic writing, the articles analysed have clearly demarcated sections that facilitate determining precisely which pronouns belong to stating goals (for example) in the 400000 -word corpus. We recognise that such boundaries are more difficult to delineate in the current situation, knowing that speakers sometimes digress and may completely fail to address the subject matter.

The current study differs from the foregoing in several ways. First, it is not a study of an individual politician's speech; rather, it characterises the central pronouns in a two-session nationally organised presidential debate involving twelve different participants and encompassing eight diverse themes. Second, the study is grammatical and not DA, CDA, or pragmatics-oriented. Consequently, all the central pronouns will be accounted for quantitatively and qualitatively. Third, the corpus size will be determined as a starting point, unlike in many of the studies reviewed. Finally, the fact that most, if not all, of the studies reviewed have not analysed presidential debates with that many participants and themes and have been limited in scope in terms of pronoun coverage provides a further justification for the current endeavour.

\section{Methodology}

\subsection{Nature and Source of Data}

The spoken text data is derived from the audio recording of the Nigeria Election Debate Group (NEDG)-organised presidential debate held on 22 March 2015 in Abuja, Nigeria and uploaded onto the World Wide Web. There were two sessions with separate moderators.

\subsection{Participants}

Thirteen presidential candidates representing thirteen political parties were scheduled to participate in the debate as follows: Tunde Anifowoshe Kelani (Action Alliance: AA), Dr Mani Ibrahim Ahmed (African Democratic Congress: ADC), Adebayo Musa Ayeni (African People's Alliance: APA), Rafiu Salau (Alliance for Democracy: AD), Alhaji Ganiyu O. Galadima (Allied Congress Party of Nigeria: ACPN), Chief Sam Ekeh, Ph. D (Citizens Popular Party: CPP), Chief Ambrose Albert Owuru (Hope Democratic Party: HDP), Muhammadu Buhari (All Progressive Peoples Party: APP), Professor Comfort Oluremi Sonaiya (KOWA Party: KOWA), Chief Martin Onovo (National Conscience Party: NCP), Dr Goodluck Ebele Jonathan (Peoples Democratic Party: PDP), Chief Godson Mgboli Okoye (United Democratic Party: UDP), and Chief Chekwas Okorie (United Progressive Party: UDP). Because Muhammadu Buhari who incidentally won the election failed to turn up for the debate, there were twelve participants (Subsequent in-text references to the candidates will be on party acronym basis).

\subsection{The Questions}

Each participant was given three minutes to make an opening remark, another three minutes to respond to each question and one minute to round off. This translates to 22 minutes per participant and 264 minutes altogether. 
The questions posed are listed sequentially with their themes enclosed in brackets thus:

Q1 (Motivation): "Why do you want to be president of Nigeria?"

Q2 (Power): "What do you intend to do (...) to guarantee steady power supply in Nigeria?"

Q3 (Oil): "How do you intend to tackle the problem of (...) oil theft?"

Q4 (Corruption): "What will be your template for tackling corruption?"

Q5 (Security):"What strategic policy direction would you put in place to guarantee the security or safety of life and property of Nigerians, to rehabilitate the victims of insurgency in the North East, reconstruct the zone and eventually bringing back the Chibok girls?"

Q6 (Education): "What are your immediate and long-term plans to restore dignity to our education?"

Q7 Agriculture): "What specific plans do you have (...) to address the issue of agriculture in such a way that it will be useful to industries and also bring money into the pockets of our people?"

\section{Q8: Round off}

\subsection{Data Collection}

The text of the transcript of the 2015 Presidential Debate was downloaded using https://youtu.be/MGwkZr3 as link. The audio tapes were listened to several times and then accurately transcribed. The corpus was carefully studied to identify and mark all the central pronouns therein. There occurred 23 representing $58 \%$ of the central pronouns in English as follows: I, me, myself, my, we, us, ourselves, our, you, yourselves, your, he, him, himself, his, herself, it, itself, its, they, them, themselves, their. It is these 23 central pronouns with a combined frequency of 2409 that constitute the data for the study.

\subsection{Problems}

A few problems occurred. The first session's tape ended abruptly a few seconds into HDP's response to Q5. Similarly, AD and ADC's responses to Q2 ended and started midstream respectively. Thus, though twelve candidates participated in the debate, only in Q1, Q3 and Q4 were their responses fully recoverable. There were eight in Q5, seven in Q2, and five in respect of Q6, Q7 and Q8. This brings the total recovered responses to 66 instead of 96 and the duration to approximately 210 minutes instead of 264.

\subsection{Corpus Size}

After confirming the accuracy of the orthographic transcription, the size of the corpus was determined by manually counting the words contained in each candidate's response to each question. The total number of words was 25 469. On the average, therefore, 385 words were recorded per response, 2122 per candidate, 3183.63 per question, and 121 per minute. Table 1 shows the full detail.

Table 1. Size of the corpus

\begin{tabular}{|c|c|c|c|c|c|c|c|c|c|c|c|c|c|}
\hline \multicolumn{4}{|c|}{ Questions } & \multicolumn{5}{|c|}{ Political } & \multicolumn{5}{|c|}{ Parties } \\
\hline & $\mathrm{AA}$ & $\mathrm{AD}$ & $\mathrm{ADC}$ & APA & $\mathrm{ACPN}$ & CPP & HDP & KOWA & $\mathrm{NCP}$ & PDP & UDP & UPP & Total \\
\hline Q1 & 404 & 308 & 435 & 354 & 423 & 365 & 408 & 379 & 428 & 503 & 403 & 466 & 4876 \\
\hline Q2 & 526 & 162 & 269 & 390 & 326 & 384 & 433 & 0 & 0 & 0 & 0 & 0 & 2490 \\
\hline Q3 & 508 & 384 & 373 & 372 & 416 & 399 & 471 & 314 & 495 & 496 & 504 & 429 & 5168 \\
\hline Q4 & 311 & 341 & 365 & 389 & 309 & 365 & 404 & 211 & 442 & 525 & 444 & 443 & 4549 \\
\hline Q5 & 0 & 0 & 0 & 361 & 0 & 422 & 128 & 352 & 407 & 509 & 506 & 495 & 3180 \\
\hline Q6 & 0 & 0 & 0 & 0 & 0 & 0 & 0 & 324 & 466 & 546 & 544 & 418 & 2298 \\
\hline Q7 & 0 & 0 & 0 & 0 & 0 & 0 & 0 & 286 & 335 & 541 & 531 & 430 & 2123 \\
\hline Q8 & 0 & 0 & 0 & 0 & 0 & 0 & 0 & 125 & 335 & 193 & 178 & 119 & 785 \\
\hline Total & 1749 & 1195 & 1442 & 1866 & 1474 & 1935 & 1851 & 1991 & 2743 & 3313 & 3110 & 2800 & 25469 \\
\hline
\end{tabular}

\subsection{Analytical Framework}

Quirk et al.'s (1985) descriptive framework for pronouns generally and the central pronouns particularly was the analytical framework chosen as already indicated. Its choice is justified by its explicitness and comprehensiveness among other features. Simple percentages complement the analysis of data.

\section{Analysis of Data and Discussion of Findings}

The analysis of data and discussion of findings cover typological distribution, semantic manifestation, thematic 
distribution, and textual illustration. To begin with, a frequency count of the 23 central pronouns was undertaken in order to determine their relative significance statistically. The 1st person plural pronoun we was the most frequent. It had 823 occurrences representing $34.2 \%$ and $3.23 \%$ of the data and corpus respectively and featured 32.31 times in 1000 words. Closely following in descending order are you (319), it (315), I (211), they (197), and our (174). The rest are them, their, us, my, he, your, me, its, his, ourselves, himself, themselves, him, itself, myself, yourselves, and herself. With a single occurrence representing $0.04 \%, 0.004 \%$ and 0.04 respectively of the same parameters, the reflexive pronoun herself was the least occurring. While further details are delayed till 4.4 below, a few pertinent remarks need to be made at this juncture. The finding that the 1st person plural we was the most recurring supports that of Hamdaoui (2015); however, the report that I, our and you were sequentially the next most frequent forms runs contrary to what was seen here. Similarly, the comparatively high occurrence of 1 st person singular, $I$, tends to agree with Flores-Ferrañ's (2017) findings on its use in debates by Donald Trump.

\subsection{Typological Distribution of the Central Pronouns}

All the central pronouns constituting the data were assigned to their appropriate subclasses to determine their level of representation. Table 2, adapted from Quirk et al. (1985, p.346), displays the outcome. Non-occurring forms are asterisked while the frequency of those found is enclosed in brackets.

Table 2. Typological distribution of the central pronouns

\begin{tabular}{|c|c|c|c|c|c|}
\hline & $\begin{array}{l}\text { Personal } \\
\text { Subjective Case }\end{array}$ & $\begin{array}{l}\text { Pronouns } \\
\text { Objective Case }\end{array}$ & Reflexive Pronouns & $\begin{array}{l}\text { Possessive } \\
\text { Determinative Function }\end{array}$ & $\begin{array}{l}\text { Pronouns } \\
\text { Independent Function }\end{array}$ \\
\hline \multicolumn{6}{|l|}{ 1st Person } \\
\hline Singular & I (211) & me (23) & myself (2) & my (48) & $*$ mine \\
\hline Plural & we (823) & us (64) & ourselves (9) & our (174) & *ours \\
\hline \multicolumn{6}{|l|}{ 2nd Person } \\
\hline Singular & you (10) & you (36) & *yourself & *your & *yours \\
\hline Plural & you (212) & you (61) & yourselves (2) & your (27) & *yours \\
\hline \multicolumn{6}{|l|}{ 3rd Person } \\
\hline Singular Masculine & he $(30)$ & $\operatorname{him}(2)$ & himself (3) & his (10) & *his \\
\hline Singular Feminine & $*$ she & *her & herself (1) & *her & *hers \\
\hline Singular Non-person & it (206) & it (109) & itself (2) & its (12) & *its \\
\hline Plural & they (195) & them $(67)$ & themselves (3) & their $(67)$ & *theirs \\
\hline
\end{tabular}

Table 2 above shows clearly that there are 40 distinct forms of the central pronouns in English comprising 16 each of personal and possessive subtypes and eight of reflexives. It also shows a total manifestation of 27 forms, accounted for by you and $I$. Fourteen (52\%) were personal pronouns, seven (26\%) were reflexive pronouns, and six $(22 \%)$ were possessive pronouns. Even though personal pronouns and reflexive pronouns were proportionately represented ( $88 \%$ each) and possessive pronouns were quite low $(38 \%)$, the frequency of occurrence of each subclass differed markedly. Again, personal pronouns occurred with far greater frequency than the others, representing $85 \%$ of the data with 2049 occurrences and manifesting as 1st person (1121), 2nd person (319), and 3rd person (609) in the number of times indicated. In sharp contrast, the reflexives recurred only 22 times (1\%), featuring as 1st person (11), 2nd person (2), and 3rd person (9). Possessive pronouns fared better, manifesting 338 times $(14 \%)$ as determinatives only. Thus personal pronouns were 100 times more frequent than reflexive pronouns and 14 times more recurring than possessive pronouns.

\subsection{Semantic Manifestations of the Central Pronouns}

\subsubsection{Person Contrast}

Approximately one-half the pronouns the debaters chose was 1st person pronouns (1354 or 56\%); one-quarter was 2 nd person (348 or 15\%) and one-third was 3rd person pronouns (707 or $29 \%$ ). This makes 1 st person contrast the highest and 2nd person contrast the lowest. Personal pronouns represent 85\% (2049) whereas possessive pronouns and reflexive pronouns represent $14 \%$ (338) and 1\% (22) respectively of the person contrast made. It therefore follows that personal pronouns made the highest selection from the subsystem of grammatical person.

\subsubsection{Number Contrast}

Plural pronouns were far more recurring than singular pronouns. While they accounted for $71 \%$ of the total number contrast made with 1704 occurrences, singular pronouns represent $29 \%$ (705). These were only slightly 
higher than what was recorded for personal pronouns, where the plural forms represent $69 \%$ (1422) and singular $31 \%$ (627). It was lower still in respect of reflexive pronouns with $36 \%(8)$ singular and $64 \%$ (14) plural. With the possessive a dominance of plural over singular was evident, as a respective percentage of 79 (268) and 21 (70) was found. In more specific terms, there was a huge difference between singular and plural forms with particular reference to 1st person and 2nd person, and this is irrespective of whether the subclass is personal, reflexive or possessive pronoun. On personal pronouns, for instance, the frequency of 1st person singular $I$ (211) and that of 1st person plural we (823) is at an approximate ratio of 4:1 in favour of the latter. Why was we chosen approximately four times more frequently than $I$ ? Similarly, why was us (64) chosen almost three times as often as me (23) or ourselves (9) over four times more frequently than myself (2) or our (174) three and a half times more frequently occurring than $m y(48)$ ? Could the need not to assert the self explain the preference for semantically inclusive forms rather than those that are exclusive? When the forms are examined in their context of use in 4.4 below, it would be clear that the need to suppress the speaker's individuality in order to gain voters' support partly explains why1st person plural we was chosen four times more often than its singular counterpart $I$, for instance.

There was also a dominance of plural over singular with respect to 2 nd person pronouns. The former was approximately seven times more frequent than the latter as their total occurrences of 302 and 46 respectively show. Specifically, plural you (273) was six times more recurring than singular you (46) with respect to personal pronouns. The singular reflexive (yourself) and possessive (your, and yours) did not occur, but there was the plural reflexive pronoun yourselves (2) and possessive determiner your (27). As Table 2 shows, yours functioning independently as subject or complement was absent. The reason for the dominance of plural over singular with respect to 2 nd person pronouns is quite different from that of 1 st person pronouns. No caution needed to be exercised here as the referents were simply one, or more than one, person. No dominance was however observed with the 3rd person pronouns; rather, singular pronouns (375) were only slightly higher occurring than plural pronouns (360). It was the dominant 3rd person singular form, accounting for $84 \%$ with its 315 occurrences. With the exception of subjective case $h e$, the rest were very low occurring indeed and these include the personal pronoun objective case him (2), the reflexives himself (3), herself (1) and itself (2), and the possessive determiners his (10) and its (12). On its own part, the plural was boosted by the pronoun they (195), its objective counterpart them (67) as well as the possessive determiner their (67). The reflexive themselves (3) was low occurring. Like theirs, independent possessives his, hers, and its, together with determiner possessive her, did not manifest. Similarly, she and its objective case counterpart her did not occur as personal pronouns.

\subsubsection{Gender Contrast}

Since only 3rd person singular pronouns select from the system of gender, all the 375 instances of usage made gender contrast as follows: Neuter gender, boosted by $i t$, was dominant (88\%); masculine gender accounted for $12 \%$ while feminine gender represents $0.03 \%$. This trend is explained by the fact that issues rather than personalities formed the subject matter of the debate. Even where persons were referred to, the ratio of masculine to feminine was 22:1. As the context of use shows shortly, most debaters simply allowed the convention of replacing non-gender specific forms with masculine gender to prevail. The single occurrence of feminine herself was indeed an attempt at fairness to both sexes, which was not sustained as the speaker quickly reverted to masculine he (See (35) below)). Personal pronouns were the dominant subclass in gender distinction, representing 93\% (347); reflexive and possessive pronouns accounted respectively for $1.6 \%$ (6) and $6 \%$ (22). The 3rd person singular feminine subjective (she) and objective (her) were not found, neither were their possessive counterparts her and hers.

\subsubsection{Case Distinction}

Case distinction was made in a total of 2387 instances of central pronoun occurrence. Subjective case was dominant with 1687 representing $71 \%$; objective case and genitive case accounted for $15 \%$ and $14 \%$ with 362 and 338 manifestations respectively. With respect to the seven personal pronouns that selected subjective case, 1 st person plural pronoun, we, was the most prominent, accounting for $35 \%$. It was distantly followed by 2 nd person plural pronoun you $(9 \%)$, 1st person singular pronoun $I(13 \%)$, 3rd person singular pronoun (neuter) it (12\%), 3rd person plural pronoun they (11.6\%), 3rd person singular pronoun (masculine) he $(2.1 \%)$, and 2nd person singular pronoun you $(0.6 \%)$. While 3 rd person singular pronoun (feminine) she never featured as subject, plural personal pronouns (1230 or $73 \%$ ) dominated their singular counterparts (463 or $27 \%$ ) as subjects.

Personal pronouns manifesting objective case occurred in the following descending order of magnitude: it (30\%), them (19\%), us (18\%), plural you (17\%), singular you (10\%), me (6.4\%), and him (0.6\%). Unlike subjective case, the plural objective case pronouns were only slightly higher than the singular ones; they represent $53 \%$ (192) 
while the latter make up $47 \%$ (170).Again, her, the objective case counterpart of the 3rd person singular pronoun feminine she, did not manifest. You and it are the only two pronouns that maintain a single form for both subjective case and objective case and they recurred far more as subject than as object, as their $70 \%$ (222) and 65\% (206) representation respectively show. Lastly, the genitive case forms were all determinatives (our, their, my, your, its, and his); the independent subtype was absent. The plural genitive case was dominant (268 or 79\%), as the singular form was quite low. Similarly, 1st person, boosted by the plural our, recurred the most (222 or 66\%). The need not to overtly assert the self could explain why our occurred 3.6 times more than $m y$. In summary, the dominance of subjective case over objective case means that most of the personal pronouns were initiators rather than recipients of the verbal actions expressed while the non-occurrence of the independent genitive case confirms the acclaimed rarity of some of its forms, notably its (Quirk et al., 1985, pp.361-362).

\subsection{Thematic Distribution of the Central Pronouns}

Table 3 displays the frequency of individual forms relative to theme.

Table 3. Frequency distribution of the central pronouns by theme

\begin{tabular}{lllllllllllll}
\hline $\begin{array}{l}\text { Central } \\
\text { Pronouns }\end{array}$ & Q1 & Q2 & Q3 & Q4 & Q5 & Q6 & Q7 & Q8 & TOTAL & $\begin{array}{l}\text { \% of } \\
\text { Data }\end{array}$ & $\begin{array}{l}\text { \% of } \\
\text { Corpus }\end{array}$ & $\begin{array}{l}\text { Freq in1000 } \\
\text { words }\end{array}$ \\
\hline We & 161 & 94 & 176 & 124 & 115 & 55 & 66 & 32 & 823 & 34.2 & 3.23 & 32.31 \\
You & 48 & 39 & 38 & 92 & 26 & 29 & 33 & 14 & 319 & 13.2 & 1.25 & 12.53 \\
It & 41 & 34 & 86 & 63 & 31 & 31 & 19 & 9 & 315 & 13.1 & 1.24 & 12.39 \\
I & 90 & 11 & 32 & 39 & 17 & 14 & 2 & 6 & 211 & 8.8 & 0.83 & 8.28 \\
They & 17 & 14 & 56 & 36 & 40 & 18 & 14 & 0 & 195 & 8.1 & 0.77 & 7.66 \\
Our & 37 & 7 & 35 & 24 & 22 & 23 & 19 & 7 & 174 & 7.2 & 0.68 & 6.83 \\
Them & 12 & 10 & 16 & 5 & 15 & 1 & 8 & 0 & 67 & 2.8 & 0.26 & 2.63 \\
Their & 7 & 3 & 11 & 12 & 23 & 3 & 8 & 0 & 67 & 2.8 & 0.26 & 2.63 \\
Us & 18 & 7 & 11 & 13 & 3 & 4 & 5 & 3 & 64 & 2.7 & 0.25 & 2.51 \\
My & 23 & 0 & 6 & 10 & 1 & 6 & 2 & 0 & 48 & 2.0 & 0.19 & 1.89 \\
He & 1 & 2 & 3 & 15 & 3 & 5 & 0 & 1 & 30 & 1.23 & 0.12 & 1.18 \\
Your & 4 & 8 & 4 & 8 & 0 & 2 & 0 & 1 & 27 & 1.12 & 0.11 & 1.06 \\
Me & 13 & 2 & 2 & 2 & 0 & 0 & 1 & 3 & 23 & 0.95 & 0.09 & 0.90 \\
Its & 4 & 3 & 1 & 0 & 1 & 1 & 1 & 1 & 12 & 0.5 & 0.05 & 0.47 \\
His & 2 & 0 & 1 & 4 & 2 & 1 & 0 & 0 & 10 & 0.42 & 0.04 & 0.39 \\
Ourselves & 1 & 0 & 1 & 6 & 1 & 0 & 0 & 0 & 9 & 0.37 & 0.035 & 0.353 \\
Himself & 0 & 0 & 0 & 0 & 2 & 1 & 0 & 0 & 3 & 0.12 & 0.01 & 0.08 \\
Themselves & 0 & 1 & 0 & 2 & 0 & 0 & 0 & 0 & 3 & 0.12 & 0.01 & 0.08 \\
Him & 0 & 0 & 1 & 1 & 0 & 0 & 0 & 0 & 2 & 0.08 & 0.01 & 0.08 \\
Itself & 0 & 0 & 0 & 1 & 0 & 1 & 0 & 0 & 2 & 0.08 & 0.01 & 0.08 \\
Myself & 2 & 0 & 0 & 0 & 0 & 0 & 0 & 0 & 2 & 0.08 & 0.01 & 0.08 \\
Yourselves & 0 & 0 & 1 & 0 & 0 & 0 & 0 & 1 & 2 & 0.08 & 0.01 & 0.08 \\
Herself & 0 & 0 & 0 & 0 & 1 & 0 & 0 & 0 & 1 & 0.04 & 0.004 & 0.04 \\
\hline TOTAL & 482 & 235 & 481 & 457 & 303 & 195 & 168 & 74 & 2409 & 9.46 & 94.6 & \\
\hline & & & & & & & & & & & &
\end{tabular}

As Table 3 graphically displays, we recurred the most in Q3 and Q1 and you in Q4 (It was fairly evenly distributed in the rest, though), while nearly half the occurrence of $I$ was in Q1 where candidates stated their motivation for wanting to be president. The highest incidence of $i t$ usage was in Q3 and Q4 while that of they was recorded in Q3 and Q5. Notice that 1st person forms (inclusive of our, my and me) were either generally more occurring in Q1 or occurred only in that theme (myself). Most of the other forms were more evenly distributed.

When viewed against the total pronoun frequency in each theme, however, indications emerge that the concentration of each central pronoun relative to the others was determined by theme. For example, whereas it was least frequent numerically in $\mathrm{Q} 8$, the highest proportion of pronoun we relative to others occurred in that theme (43\%). Its singular counterpart $I$ accounted for $19 \%$ of pronouns in Q1 where it also recorded the highest frequency. The highest concentration of possessive our occurred in Q6, although it was more frequently used in Q2 and Q3. To have a clearer picture of how the pronouns behaved statistically relative to each theme's data, a quick table showing the most recurring forms can be drawn thus: 
Table 4. Proportion of some central pronouns relative to each theme's data

\begin{tabular}{lllllllll}
\hline & Q1 & Q2 & Q3 & Q4 & Q5 & Q6 & Q7 & Q8 \\
\hline Frequency of Pronouns & 482 & 253 & 481 & 457 & 303 & 195 & 168 & 74 \\
Proportion in Percentage & & & & & & & & \\
We & 33 & 40 & 37 & 27 & 38 & 28 & 39 & 43 \\
You & 10 & 17 & 8 & 20 & 9 & 15 & 15 & 19 \\
It & 9 & 15 & 18 & 14 & 10 & 16 & 11 & 12 \\
I & 19 & 5 & 7 & 9 & 6 & 7 & 12 & 8 \\
They & 4 & 7 & 12 & 8 & 13 & 9 & 8 & 0 \\
Our & 8 & 3 & 7 & 5 & 7 & 12 & 1 & 9 \\
\hline
\end{tabular}

Because of the problems pointed out in 3.4 above, where, for instance, candidates' responses to some questions could not be recovered fully from the downloaded material, particularly their responses to Q5-Q8, it is somewhat difficult to make generalisations with respect to theme. Nevertheless some useful observations and remarks can validly be made pertaining to theme and types and frequency of pronouns. The 23 central pronouns were not all used in response to every question. For instance, 18 each occurred in Q3 and Q4, 17 in Q1, 16 each in Q5 and Q6, 14 in Q2, 12 in Q7, and 11 in Q8.Although Q1, Q3 and Q4 presented the largest corpus sizes and the highest number and frequency of pronouns (These were the only themes in which all 12 participants' responses were contained in the download), it was Q2 which ranked 7th in corpus size that recorded the highest proportion of pronouns relative to the corpus. This was $10.2 \%$ or 102 per 1000 words. It was closely followed by Q4 (10.1\%) and Q1 (9.9\%), Q5 (9.53\%), Q8 (9.43\%), Q3 (9.31\%), Q6 (8.5\%), and Q7 (5.4\%) in that descending order. When the pronouns are next examined in the context of use, it would be seen precisely what choices were made and how they combined one with another to make meaning and achieve the debaters' goals. Meanwhile, Table 5 exposes these facts vividly.

Table 5. Pronoun frequency relative to theme and corpus size

\begin{tabular}{lllllllll}
\hline & Q1 & Q2 & Q3 & Q4 & Q5 & Q6 & Q7 & Q8 \\
\hline Corpus Size & 4876 & 2490 & 5168 & 4549 & 3180 & 2298 & 3123 & 785 \\
No. of Pronouns & 17 & 14 & 18 & 18 & 16 & 16 & 12 & 11 \\
Frequency & 482 & 253 & 481 & 457 & 303 & 195 & 168 & 74 \\
\% of Corpus & 9.9 & 10.2 & 9.31 & 10.1 & 9.53 & 8.5 & 5.4 & 9.43 \\
Rate in1000 words & 99 & 102 & 93 & 101 & 95.3 & 85 & 54 & 94.3 \\
\hline
\end{tabular}

\subsection{Textual Functions Illustrated}

During the 2015 Presidential Debate questions aimed at exposing the respondents' general potential competence in governance were asked. Since the questions were meant to probe the candidates' grasp of the problem and find out whether or not they have workable solutions, any competent speaker will justify the thesis by recognising or identifying the problem, articulate the solutions to the problem and justify same, and then conclude. (These are indeed the textual functions that the central pronouns were used to perform.) Moreover, the debaters' goal was primarily to woo votes for their parties. How the central pronouns served in texturing the respondents' answers to achieve all this is illustrated in this final segment of data analysis and discussion of results using person, number, gender, and case as bases. As many of the themes and individual candidate's responses as are relevant will be excerpted without being unmindful of the dangers of over-exemplification.

Two observations need to be made at this juncture. First, the central pronouns never functioned in isolation. They combined one with another in executing the different functions, sometimes leading to overt overlap. Consequently, all the central pronouns in a given excerpt are italicised, with those directly focused upon further marked. Second, $62 \%$ (41) of the responses either began or ended with an expression of appreciation (to the organisers of the debate, the audience, co-debaters, and Nigerians generally) and you collocating with thank was dominant. Others are $m e$ as initiator of the appreciation process in the let-type imperative and us as beneficiary, contrasting with $I$, their, and we. These are not illustrated separately but are integrated with others, beginning with recognising the problem.

\subsubsection{Recognising/Identifying the Problem and Justifying the Thesis}

\section{Person}

The choice of person varied according to theme and candidates' idiosyncrasies. In response to Q1 which is 
motivation for contesting, for instance, speakers made generous use of the 1st person singular in recognising or identifying the problem and justifying the thesis because they needed to assert themselves as eligible and capable candidates. Thus, contrary to Carey et al.'s (2015) report, the instances of $I$ and me usage (my and myself inclusive) were assertive, as the following excerpts show. Notice however that the second occurrence of $I$ in (3) and the single one in (13) is subtly opinionated rather than overtly assertive, which agrees with Hắkansson's (2012) report that the form conveys personal opinion (See also (9) below)).

1) Why $\boldsymbol{I}$ want to be president of Nigeria is because $\boldsymbol{I}$ know that there are problems to be solved in this country and $\boldsymbol{I}$ am offering $\boldsymbol{m y s e l} f$ based on the fact that $\boldsymbol{I}$ have been nominated by $\boldsymbol{m} \boldsymbol{y}$ political party (...) (Q1CPP)

2) Thank you very much. $\boldsymbol{I}$ am making myself available for the office of president of the Federal Republic of Nigeria because $\boldsymbol{I}$ want things to change. $\boldsymbol{I}$ want $u$ s to move away from where we are to where we should be. (Q1UPP)

3) $\boldsymbol{I}$ thank you and let $\boldsymbol{m} \boldsymbol{e}$ use this unique opportunity to thank Nigerians for their total commitment in (sic) the electoral process. In the first place, $\boldsymbol{I}$ believe Nigerians will vote for $\boldsymbol{m} \boldsymbol{e}$ and $\boldsymbol{I}$ want them to vote for $\boldsymbol{m} \boldsymbol{e}$ because of the progress we have made over these past four years (...) (Q1PDP)

The person mix in the other themes was however more heterogeneous probably because there was no compelling reason to assert the self. As the following excerpts show, there were the 1st, 2 nd and 3rd person forms making references to Nigerians and entities as appropriate.

4) The challenges we have seen in the educational sector (...) are basic challenges. In some cases, it is as simple as the roof is not there (...) In other cases, it is that you don't have enough teachers. (Q6NCP)

5) $\boldsymbol{W e}$ are talking about equipping our armed forces. Is there any year we didn't have a budget for our armed forces? How many times did we budget for the Benin-Sagamu? All these problems we will keep analysing, reanalysing till we deal with the root cause, which is the leadership problem. (Q5NCP)

6) There are two issues to the problems of corruption in Nigeria. One, it has to do with the quality of leadership (...) Secondly, it also has to do with our attitude as a people.(Q4ADC)

Number

Both singular and plural pronouns jointly functioned to recognise the problem as the following excerpts show. Notice the generic use of pronoun we in (7) and its rhetoric use in (8). Notice also that while our makes reference to the incumbent president's government in the one it serves as a pro-form for Nigeria's in the other.

7) Thank you. When we talk about agriculture, it's one sector that people who are honest agree that really our approach (...)'s really changed. In terms of the import bills you know that we dropped by almost two-thirds(...) and $I$ give example (...) (Q7PDP)

8) Thank you. Let $\boldsymbol{m e}$ admit that some impetus has been given to the agricultural sector and so there is visible improvement (...) There is something wrong with our policy yet. We have made fertiliser available, people are improving on the yield of their farms, but at the same time we have cattle eat up all these things. (Q7UPP)

However, there were instances where either the singular was more visible because the speaker was more assertive and specific (e.g. (9)), or the plural was more prominent because the speaker wanted to identify with the "collective conscience" (e.g., (10). Indeed, the singular $I$ featured in 75 per cent of the responses.

9) Thank you. I must say the primary purpose of government, we all know, is to give security and welfare to its citizenry. And we have seen in recent times progressively Nigerians have become insecure (...) It started with agitation, which $\boldsymbol{I}$ think has been addressed half-heartedly. (Q5HDP)

10) Thank you. This is where the challenge really lies also apart from security for Nigeria at this time. The falling price of oil is going, is staring $\boldsymbol{u s}$ in the face and $i t$ 's like what are we going to do to continue to run our government.(Q3KOWA)

In (11) below, the contrastive use of the pairs we / us and $I / m e$ aided by a sequence of imperative clauses enabled the speaker to identify with the voting public and positively announce his candidacy in the same breath.

11) Fellow Nigerians! We are on the threshold of history and $\boldsymbol{I}$ commend $\boldsymbol{u s}$ for creating this opportunity for $\boldsymbol{u s}$ to interact as Nigerians. Don't look at $\boldsymbol{m e}$ as someone (...) that wants to be your overload. See $\boldsymbol{m e}$ as one Nigerian who seems to know what the problems are and who has the courage to proffer some solutions. (Q1UDP) 
Gender

Probably the most remarkable feature of gender contrast found in the context of identifying the problem and justifying the thesis is the sexist use of masculine he as referent for a preceding assertive pronoun (12) and a personal dual gender noun teacher (13).

12) By the time we begin to admit people into universities by quota system, by educationally disadvantaged, in such a way that somebody who had scored highly is now denied admission in favour of somebody who scored very poorly on account of where he comes from (...) (Q6UPP)

13) If you have a situation where the teacher failed the exam of the class, which $I$ think happened in Edo, it's corruption. How did he get recruited? (Q6NCP)

In (14) below, two coordinated noun phrases are replaced with the masculine gender he. While the headword of the one is morphologically masculine the other is not. The choice of masculine gender is informed by the predominantly male world structure referent for the second headword even though there are now professional female combatants.

14) But what do we have these days? The educational system is bankrupt. How will a policeman or a soldier send his child to school? We are not even thinking about that. (Q6UDP)

Lastly, neuter gender is illustrated in (15). Notice that while the referents of the first two it-occurrences (the one to an abstract noun robbery, and the other to a concrete noun armoured personnel carrier) can be recovered syntactically, the third's is only textually recoverable and this is solution to the issue of insecurity.

15) Well $I$ want to emphasise that security challenges are not limited to the North East. Just a few weeks back we know about the robbery in Lekki Phase I in Lagos. It lasted over an hour. At the gate of the estate there is an armoured personnel carrier. It did not respond (...) It's not about money, money, money. We must have the right values as a people. (Q5NCP)

Case

Case distinction was employed in recognising the problem and justifying the thesis. Pronouns manifesting subjective case helped the speaker to reveal the effect of corruption in Nigeria ( $I$ and $i t)$ and identify its perpetrators (collective we) and symbols (they) in (16) below.

16) First of all, $\boldsymbol{I}$ would like to say that the fact of our underdevelopment is not an act of God. It is because we are corrupt. We pocket (...) monies that are supposed to be used to develop our society. They are diverted for private consumption. (Q4KOWA)

The 3rd person plural subjective case they, a referent for the thieves used repeatedly in a sequence of interrogative and affirmative sentences, most effectively served to recognise and identify the problem as this relates to Nigeria's oil sector. Here is the context.

17) Nigeria is losing 400000 (...).That's 16 million dollars (...).Who are the thieves? Where are they? (...) They are living among us. And why are they doing this? They are doing this because they don't believe in this country. They don't have any hope in this country. They are just after the fact that they want to make it at all cost. (Q3AA)

The objective case form them, used as a referent for the broken-down/disused/stolen blades to explain the cause of unsteady power in Nigeria, also featured in interrogatives (The questioning technique appears to be idiosyncratic for AA).

18) Thank you very much. Why are we where we are today? (...)Our hydro-dams have sixteen blades. As of today how many blades are working there? Maybe four! (...)What's wrong with the other twelve blades? I mean, what is stopping them from working? (Q2AA)

Genitive case is shown in the following excerpt where the determinative, their, refers to pipeline vandals (See also our in (16) and (18) above)).

19) Yes, thank you. What we are experiencing in the oil and gas industry is as a result of unemployment (...) that is why they now focus their mind on destroying the pipelines and then, I mean, stealing the oil product. (Q3AD)

\subsubsection{Specifying Actions to be Taken and Justifying Same}

Person

The 1st person pronouns served to identify the individuals/entities specifying the actions to be taken and the beneficiaries of such actions as we and our /us respectively show in the following excerpts. Notice that in (21), 
the speaker, coming from the vantage point of incumbency, enumerates actions already taken by his government instead, with a promise to further consolidate on them (See also (23) and (25)). This shows that situational context influences pronominal meaning and function.

20) In UPP (...), we decided that if this cankerworm must be fought frontally, it must start from the top (...) And so we believe that asset declaration is not only going to be compulsory, it will be public. $\boldsymbol{W e}$ also believe that what is called security vote(...) must be tied to security matters and must be accounted for(...)We also said that immunity will be limited to civil matters.(Q4UPP)

21) $\boldsymbol{W e}$ 've recovered most of our territories (...) and the people have to move back. How do they settle?(...)That $\boldsymbol{w} \boldsymbol{e}$ 've raised quite some money (...) Then $\boldsymbol{w e}$ have what is called PINE. But the key thing is how do we prevent such and how do we provide security for all Nigerians? (...)We will continue to build capacity. (Q5PDP)

22) The KOWA Party will seek to address these dimensions (...) With respect to our schools there must be a total reorientation because the reality is that education has not led to the transformation of our society. This is a blithe on $\boldsymbol{u s}$ and therefore there must be a review of our curriculum to orient it (Q6KOWA).

In the following excerpts illustrating the 2nd person pronoun you, its meaning is generic except in the first sentence of (23) where it refers to the audience. Its occurrence in clauses of different polarities exposes the danger in taking or not taking a specified action.

23) In terms of import bill, you know we dropped by two-thirds (...)So how do we encourage young people to go into agriculture?(....)That's why we are looking at agric as a business (...)We are looking at the total value chain (...)So we are no longer talking about groundnut pyramid (...) When you export raw material, you are exporting labour. (Q6PDP)

24) Until you, you base the running of this system on people that are competent (...) you can't expand the space. And if you don't expand the space, you create desperation (...) and corruption (...) will follow (...)We must rectify that system (Q4UDP)

Finally, 3rd person pronouns are shown in the context of specifying actions to be taken thus (Notice their diversity):

25) We have progressed significantly and we need to sustain it (...). Before 2011, Nigerians were not too interested whether they had voters card or not. It is this government that made sure that consciousness is bought and Nigerians must decide who governs them. (Q1PDP)

26) A UPP government will take steps to expunge from our laws the Land Use Law so that people (...) can use their land as collateral to attract necessary funds to go into agriculture and develop their lands (...)(Q7UPP)

Number

Plural pronouns dominated by we were far more prominent than singular pronouns in the context of specifying actions to be taken. This is an indication of collective responsibility shared by the party, the government and the people and tends to support Hắkansson's (2012) report that we conveyed institutional opinion (cf. (27)). Because the forms are as diverse (They include the emphatic use of the reflexive themselves and the repetitive use of plural we with the modal of intention will in (29) below.)) as the solutions proffered, the excerpts are chosen to reflect this reality.

27) Thank you very much (...)We believe that we can create economy big enough to provide jobs for all. And how are $\boldsymbol{w e}$ going to do that? $\boldsymbol{W e}$ (....) take 30 percent of the national income to invest in our economy. (Q1AD)

28) How do we now talk to Nigerians? How do we now create hope for Nigerians? How do we make everybody to believe in this country? We need to now as a government warm ourselves into the heart of the people so that they can have hope in Nigeria. (Q3AA)

29) $\boldsymbol{W e}$ will address fundamental issues that have been raised the way we have said today (...).We will make sure that we domestically refine and sell petrol (...).We will increase the minimum wage by reducing the maximum wage.(Q8NCP)

30) Meanwhile our armed forces must continue to receive (...) the full support in every area (...) $I$ mean, if people are going to be faced with the possibility of dying while defending their country, then they must be certain that their families will be well taken care of.(Q5KOWA)

31) We will encourage the states to take charge of some of these areas to make sure that they themselves are in control. (Q2HDP) 
Two instances of rare singular pronoun usage, the one as reference to antecedent nouns and the other as reference to the speaker himself and his party, are as follows:

32) To solve the problem of power (...) we are suggesting full deregulation of the system. It has to be fully deregulated (...) It will open up more serious investors to come. (Q2CPP)

33) And $\boldsymbol{m y}$ leadership is going to insist on opening up of the economy, on true federalism (...)And so the UPP that $\boldsymbol{I}$ stand on its platform has come with a revolutionary agenda. (Q1UPP)

Gender

The two excerpts illustrating how gender contrast featured in specifying actions to be taken embody all the issues associated with the category, namely the tendency to use the plural they/them as a replacement for singular common nouns in (34) and both sexism and adherence to the old order in (35) (See 4.2.3 above).

(34)To stamp out corruption there must be social security (...).We must do what is right: Give to the individual what is due to them. (Q4ACPN)

(35) We come back to the issue of security, how to prevent it (...).We believe in state police (...) and it is in this way that every citizen will see himself or herself as an equal stakeholder in the security of this country, so that even within $\boldsymbol{h i s}$ own small environment, if $\boldsymbol{h} \boldsymbol{e}$ sees (...) things that should be suspected, he will report to the appropriate authorities. (Q5UPP)

Case

Personal pronouns manifesting subjective case, objective case, and genitive case indicate who specifies the actions to be taken, who benefits from such actions, and who possesses the entity involved as (36)-(38) respectively show.

36) It matters a lot to prosecute offenders (...) It is high time state police comes into being because they know the terrain. We also have to look at our borders. Our borders are so porous. (Q5CPP)

37) So, the first thing you have to do to reduce this insurgency (...) is engage the youth (...) And $I$ tell you, with just 1000 hectares of land in every state (...) we will generate one million jobs.(Q5APA)

38) $M y$ party prompted $m e$ to contest on the grounds that $I$ was able to convince them as $I$ am trying to convince Nigerians today that investing in our human resources (...) will certainly be the way forward. And part of what we intend to do (...) is to put resources in our educational sector. (Q1ADC)

\subsubsection{Making Concluding Remarks}

\section{Person}

All three grammatical persons featured in candidates' concluding remarks on the responses to the questions posed. Although the 1st person plural we was generally more prominent, its singular counterpart was again the most visible with respect to Q1 and Q8, which is evidence of assertion of the self. Consider this:

39) $\boldsymbol{I}$ do not want anybody to refer to $\boldsymbol{m} \boldsymbol{e}$ as the best president you didn't have. $\boldsymbol{I}$ want to be referred to as the best president that Nigeria has had(...)I love all Nigerians. (Q8UPP)

In (40), the speaker concludes by affirming his capability and willingness to move Nigeria forward and requests Nigerians to vote for him thus:

40) And that's why $I$ 'm coming out to tell you that we have to stop this artificial problem. Nigerians must grow. We must be number one in the world and $\boldsymbol{I}$ can do it. Send $\boldsymbol{m} \boldsymbol{e}$ and $\boldsymbol{I}$ will go. Thank you very much for this opportunity. (Q1AA)

Two more examples in diverse contexts are as follows:

41) $\boldsymbol{I}$ thank all of you for listening. And on 28th, be sure to go and cast your votes. Conduct yourselves in a peaceful manner. $\boldsymbol{I}$ thank you and may God bless Nigeria. (Q8UDP)

42) $\boldsymbol{I}$ wouldn't mind to step on anybody's toes once $\boldsymbol{I}$ am within the ambit of the law to make sure that the issue of corruption is addressed (...)Thank you. (Q4CPP)

The 1st person plural featured as we mainly, as the following excerpts show. Notice the contrast in the propositional contents of both excerpts. Notice also semantic over-coding in the second where the repeated pronoun, aided by the appropriate modals, emphasises willingness and do-ability at once.

43) We are moving away from government management of the economy directly (...) Soweare encouraging theprivate sector to drive the (...) (Q3PDP) 
44) The senate report on privatisation has concluded that privatisation has failed in Nigeria. Why would anybody suggest privatisation? What has happened to all the privatised entities? We will not privatise. We will fix it. We can fix it. (Q3NCP)

The 2nd person form you rarely featured in making concluding remarks except in the context of the verb of gratitude thank where its referents are the moderator, the audience, and Nigerians as already noted above. While this is exemplified under number below, one context of its generic use is shown as follows.

45) You see (...) once you are able to encounter the source of these people that are causing the problem, once you, you stop it and they are no longer available (...) the problem of insecurity goes to sleep.(Q5APA)

In contrast, the 3rd person forms were prominent and are shown in two excerpts thus (Notice the repetition of plural they which refers to people in all but one instance):

46) And certainly, if all corrupt officers, irrespective of their standing in the society, are brought to book, it will certainly set the right punitive example that will deter others. (Q4ADC)

47) When people know how much oil per barrel is sold, they know how much production Nigeria makes because they are public numbers, they imagine the revenue, they hear a budget every year and they don't see it. Everybody does not have the same moral threshold. It is not an excuse, but these are the root causes we need to deal with before we bring in this other issue of motivating our soldiers and you can't motivate corruption. Corruption universally de-motivates. (Q5NCP)

Number

Both singular and plural central pronouns jointly functioned to conclude the responses, but there is a paucity of the former, which is illustrated first. While the referents of the 3rd person singular forms in (48) are state and support the entrepreneur respectively, the 1st person singular form is contextually assertive in (49). Here are the excerpts.

48) What we do is to ensure that each state generate (sic) its own power. Then we will support the entrepreneurs(...) It is in the constitution of Nigeria. Thank you so much. (Q2ACPN)

49) So there will be no hiding place for corrupt people. And once you plug all the holes that encourage corruption at the highest level, I can assure you the Nigerian (...) will follow you. Thank you very much. (Q4UPP)

The plural pronouns comprise the 2nd person form you (used in the context of appreciation and as reference to people in general) and we in the main.

50) So if we do the right thing as a people we will get the right results (...) What we need is the right leadership (...) Thank you very much. (Q7NCP)

51) So immediately society starts shifting away from people who cannot defend their source of income (...), people will begin to live a more descent life (...) Thank you. (Q4PDP)

The excerpt below illustrates some other plural forms used in making concluding remarks. Notice that they also manifest objective case and genitive case, referring respectively to Nigerians and Nigeria's.

52) The road map we have is for an integrated power system that will certainly give us the kind of energy we need to power our engine of growth. Thank you. (Q2ADC)

Gender

Apart from neuter no other gender contrast was observed among the central pronouns used in concluding the submissions. The two excerpts provided below show the ability of collective nouns (marked) to take the 3rd person plural they, or, its variant, as co-referents.

53) There is too much government involvement in educational institutions. So they will have to open it up to those who can manage $i t$ and make it competitive. (Q6UPP)

54) But $I$ think if the Federal Government (...) can play their role and also the host community provide jobs for this youth, they won't be involved in this type of shameful act. That is $m y$ take for now. Thank you. (Q3CPP)

Case

Central pronouns exhibiting subjective case, objective case and genitive case functioned to conclude the responses as the excerpts below respectively show. In (55), the referents are the speaker's prospective government and local entrepreneurs respectively while in (56) they are Nigerians (as a people), law enforcement agents, and the audience/moderator/ Nigerians. Note that all occurrences of you in this context indicate objective 
case. The genitive case form our makes reference to the speaker's government.

55) So (...) we will place emphasis on coal (...).We will encourage local entrepreneurs to invest in these areas (...) They deserve it. (Q2HDP)

56) So let $\boldsymbol{u s}$ restore that job to our traditional law enforcement agents. It is part of their duty. Let them do it and $I$ believe that will help that sector. Thank you. (Q3KOWA)

57) Our commitment is to make sure that it is opened up to private sector investment. We are moving away from government management of the economy directly (...) (Q3PDP)

\section{Conclusion}

Previous studies have been silent on a number of critical issues concerning the central pronouns, namely their manifestation in the corpora used compared to the number in English, subtypes and their frequency, semantic manifestation, thematic distribution, and textual functions. These have been addressed in this study, which highlight forms the focus of this concluding section.

This study has revealed a 58\% representation of the central pronouns in English with an occurrence rate of 94.6 in 1000 words and has shown that though personal pronouns and reflexive pronouns were proportionately represented, the former was a hundred times more frequent than the latter and was also fourteen times more recurring than the possessive. The1st person, 2nd person and 3rd person forms represent approximately one-half, one-quarter, and one-third respectively of the total person contrast made while a dominance of plural over singular, more pronounced with 2nd person, was seen. Neuter gender dominated, as masculine gender occurred twenty-two times more often than feminine gender. Subjective case was similarly dominant over objective case while genitive case featured determinatives only. Furthermore, the themes of the debate governed the choice and frequency of the central pronouns as seen in the 1st person subjective case forms being more concentrated in Q1 than in any other theme and the density of the 2nd person you being highest in Q4. Though we-occurrence was numerically lowest in $\mathrm{Q} 8$ and highest in $\mathrm{Q} 3$, its proportion relative to the total pronoun occurrence was higher in the former than in the latter. On textual functions of the central pronouns, the analysis has revealed that the segment of the response in Q1 where candidates recognised and justified the problem recorded more $I$-usage than where actions to be taken were specified or concluding remarks made. The person and number mix in the other segments and themes was however more heterogeneous. Finally, the analysis has also demonstrated that a speaker's idiosyncrasy influences pronominal choice. For example, KOWA almost always used the 1st person plural forms our /us in reference to Nigerians and in ways quite different from PDP's, who especially exploited we /our as referents to his government, listing its achievements to justify re-election.

Political debates are not known to have been analysed from the viewpoints of how politicians actually respond to the questions posed. To deal with this, three parameters which also double as the textual functions of the central pronouns were proposed and their workability demonstrated in 4.4 above. This can be adopted. One advantage a grammatical study like this has is that it demonstrates that when the central pronouns are analysed together as an entity rather than as discrete items their capacity to actualise debaters' goals becomes manifestly clear. This has thus enabled an account of many more central pronouns that had been ignored in previous studies because of their relative infrequency (e.g., myself and itself) to be made. The texts analysed are real and multiple, involving the same questions but diverse responses. Multiple-authored texts have the advantage of enabling the analyst to see the diversity of pronoun forms and use from the points of view of the number that constitutes the data, their frequency, and their combinatory possibility as this study has shown. This is particularly true since one is not studying the idiolect of a given politician but the use of an aspect of language in politics, namely the central pronouns.

\section{References}

Abdel-Moety, D. M. (2015). American political discourse as manifested in Hilary Clinton's interviews: A critical discourse approach. English Linguistics Research, 4(1).

Abdullahi-Idiagbon, M. S. (2010). Language use in selected Nigerian presidential election campaign speeches: A critical discourse analysis perspective. Journal of Nigeria English Studies Association, 13(2), 32-49.

Bello, U. (2013). "If I could make it, you too can make it" Personal pronouns in political discourse: A critical analysis of President Jonathan's presidential declaration speech. International Journal of English Linguistics, 3(6), 84-96. https://doi.org/10.5539/ijel.v3n6p84

Bloor, T., \& Bloor, M. (1990). The functional analysis of English: A Hallidayan approach: London: Arnold.

Boyd, M. S. (2013). Conceptual metaphor and personal pronoun in political discourse: The US 2008 presidential 
debates.

Retrieved

from http://host.uniroma3.it//linguisti/lcs_ingles/roma3/newsblog/Entries/2013/5/6/Laurea_magistrale_1_(Boyd)

Carey, A. L. et al. (2015). Narcissism and the use of personal pronouns revisited. Journal of Personality and Social Psychology, 109(3), e1-e15.https://doi.org/10.1037/pspp0000029

Christophersen, P., \& Sandved, A. (1969). An advanced English grammar. London: Macmillan.

Flores-Ferrañ, N. (2017). 'I'm very good at and maybe that's why I'm center stage'... Pronominal deixis and Trump. English Linguistics Research, 6(1), 74-86.https://doi.org/10.5430/elr.v6n1p74

Gocheco, P. M. (2012). Pronominal choice: A refection of culture and persuasion in Philippine political campaign discourse. Philippine ESL Journal, 8, 4-25. Retrieved from https://wwwresearchgate net/publications/309242644

Greenbaum, S. (1996). Oxford English grammar. Oxford: Oxford University Press.

Greenbaum, S., \& Nelson, G. (2002). Introduction to English grammar. London: Longman.

Halliday, M. A. K. (1985). An introduction to functional grammar. Edward London: Arnold.

Halliday, M. A. K., \& Matthiessen, C. M. I. M. (2004). An Introduction to functional grammar. London: Arnold.

Hắkansson, J. (2012). The use of personal pronouns in political speech: A comparative study of the pronominal choices of two American presidents. (Unpublished bachelor dissertation). Linnæus University, United States of America. Retrieved from http://www.diva-portal.org/smash/get/diva2.53116/fulltext O1pdf

Hamdaoui, M. (2015). The persuasive power of person deixis in political discourse: The pronoun "we" in Obama's speeches about the 2007-2009 financial crises as an example. European Conference on Arts \&Humanities, Official Conference Proceedings. Retrieved from http://papers.iafor.org./papers/ecah2015/ECAH2015_15702.pdf

Hasan, J. M. (2013). A linguistic analysis of in-group and out-group pronouns in Hosni Mubarak's speech. Journal of Basrah Researches (Humanities Series), 38(2), 5-24. Retrieved from http://iasj.net/iasj?func_fulltext\&lald=90135

Huddleston, R. (1984). Introduction to the grammar of English. Cambridge: Cambridge University Press. https://doi.org/10.1017/CBO9781139165785

Jespersen, O. (1933). Essentials of English grammar. London: George Allen \&Unwin Ltd.

Kuo, C. (1999). The use of personal pronouns: Role relationships in scientific journal article. English for Specific Purposes, 18(2), 121-138. https://doi.org/10.1016/S0889-4906(97)00058-6

NEDG Presidential Debate. (2015). 1st session, 12 00pm, size 258 MB.2nd session.3.00pm-5.00pm, size, 295 MB, length 01:38:11, 22 March 2015. Retrieved from wwwyoutube.com; https://youtu.be/MGwkZr3 S81

Nelson, G. (2001). English: An Essential grammar. London: Routledge. https://doi.org/10.4324/9780203464861

Oladimeji, K. O. (2010). A pragmatic analysis of President Umar Yar Adua's inaugural speech of 29th May 2007. Journal of Nigeria English Studies Association, 13(2), 50-67.

Opeibi, O. B. (2010). Language, globalisation and democratic governance: English in Nigeria's political discourse. In O. Okoro (Ed.), Nigerian English in sociolinguistic perspectives: Linguistic and literary paradigms (pp. 241-260). Lagos: Pumark Nigeria Ltd.

Quirk, R., Greenbaum, S., Leech, G., \& Svartvik, J (1985). A comprehensive grammar of the English language. London: Longman.

Radford, A. (2004). English syntax: An introduction. Cambridge: Cambridge University Press. https://doi.org/10.1017/CBO9780511841675

Scott, F. S., Bowley, C. C., Brockett, C. S., Brown, J. R., \& Goddard, P. R. (1968). English grammar: A linguistic study of its classes and structure. London: Heinemann Educational Books Ltd.

Strang, B. M. H. (1969). Modern English structure. London: Edward Arnold.

Tayyebi, M. (2012). Personal pronouns in English and Persian medical research articles. English for Specific Purposes World, 30(12). Retrieved from http://www.esp-world.info

van Dijk, T. A. (1997). What is political discourse analysis? Retrieved from http://www.discourses.org

Yusuf, Y. K., \& Olateju, M. A. (2005). Gender-related singular they: Perception of correctness in Nigerian 
English. Journal of Nigeria English Studies Association, 11(1), 131-150.

\section{Copyrights}

Copyright for this article is retained by the author(s), with first publication rights granted to the journal.

This is an open-access article distributed under the terms and conditions of the Creative Commons Attribution license (http://creativecommons.org/licenses/by/4.0/). 